\title{
Narrándose en la flexibilidad. Un análisis narrativo discursivo de la identidad en tiempos de flexibilidad laboral ${ }^{36}$
}

\author{
A Narration in Flexibility: A Narrative Speech analysis \\ on Identity in Times of Labor Flexibility
}

Vicente Sisto ${ }^{37}$ y Carla Fardella ${ }^{38}$

\begin{abstract}
Resumen
El vínculo laboral se ha hecho cada vez más flexible, transformando con ello la relación que establece el sujeto con lo social a través del trabajo. Si el trabajo fue considerado por la teoría social moderna como el principal mecanismo de integración social, a través del cual los sujetos obtienen su lugar como actores sociales, hoy esto está cambiando radicalmente. Las nuevas formas de ordenamiento social que se imponen a través del trabajo tienen como correlato la producción de nuevas subjetividades y, con ello, nuevas formas de ser actor social. La investigación que aquí se presenta asume una perspectiva narrativa discursiva, con el fin de abordar los relatos identitarios como formas de acción que nos posicionan como actores sociales. Desde esta perspectiva, se aborda la emergencia de nuevas formas de identidad bajo este orden laboral. Para ello nos hemos centrado en adultos jóvenes profesionales, considerados como los mejor posicionados para integrarse socialmente en este nuevo orden laboral. Mediante análisis del discurso, fueron analizadas 32 entrevistas. Tal como se apreciará, la figura del emprendedor libre elector, autor de su propia trayectoria, constituye el eje que estructura las narrativas, coincidiendo con algunos estudios sociológicos. Sin embargo, el estudio muestra que este eje es tensionado, indicando también cómo dicha tensión es resuelta por
\end{abstract}

36 Este trabajo ha sido apoyado por el Fondo Nacional de Investigación Científica y Tecnológica del Gobierno de Chile (FONDECYT) a través del Proyecto No 11060280.

37 Dr. en Psicología Social. Profesor Adjunto, Pontificia Universidad Católica de Valparaíso. vicente.sisto@ucv.cl

38 Psicóloga, Docente e Investigadora, Pontificia Universidad Católica de Valparaíso. carla. fardella@ucv.cl 
este trabajo de construirse a sí mismo respondiendo al orden social contingente.

Palabras claves: cambios en el trabajo, subjetividad, identidad, análisis narrativo, análisis del discurso.

\section{Abstract}

Employment links have become more and more flexible, transforming the relationship between subject and society by eliminating the identification of type of labor. If labor was considered by modern social theory as the main means of social integration by which individuals obtained their place in society, today this is radically changing. New forms of social order, imposed by work, are linked to the perception of self and its place in the social order. This article presents a discursive analysis using interview material in which 32 young professionals develop their stories as flexible workers. It employs the methodological approaches developed by discursive psychology to look into the identity of speakers. As will be seen, the figure of the entrepreneur "free elector", author of his own trajectory, is raised as the model subject guiding the construction of identity. However, the analysis shows that this axis is tense, indicating at the same time that the tension is resolved by the work of self construction relating to the contingent social order.

Keywords: changes in work, subjectivity, identity, narrative analysis, discourse analysis 


\section{Introducción}

Actualmente, una parte importante de las ciencias sociales ha asumido la tarea de abordar las consecuencias sociales y subjetivas de las transformaciones en el mundo del trabajo. En el contexto de la organización social moderna, el trabajo ha sido considerado como el principal mecanismo de vinculación social mediante el cual la acción de los sujetos es articulada, sirviendo como base y sustento de la producción social, tal como lo señalaron los clásicos de la sociología (Durkheim, Weber y Marx). Mediante el trabajo, el sujeto pone su actividad en función de la producción social, a cambio de lo cual obtiene una parte de esa producción social (a través de salario directo o indirecto), y la vez, un lugar en la sociedad, adquiriendo una identidad socialmente reconocida (Gorz, 1991).

Sin embargo, hoy el trabajo está cambiando radicalmente. Según Castells (1997), el contexto social contemporáneo se caracterizaría por: la revolución tecnológica que altera la velocidad de la producción social; las modificaciones en la geopolítica global luego de la caída del estatismo soviético; la creciente interdependencia de las economías que lleva la competencia a una escala global; y el cambio del papel del estado, ahora transformado en un desregulador de mercados. Todo esto se estaría desarrollando en el marco de una reestructuración interna del capitalismo, lo que impulsa una mayor flexibilización interna de la gestión, aumentándose el poder del capital por sobre el del trabajo. Actualmente, diversas agencias intergubernamentales, centros de estudios, así como líderes del management, demandan una mayor flexibilidad en la vinculación laboral como una condición para el desarrollo económico. De este modo, en distintos lugares del planeta el trabajo ya deja de ser un mecanismo a través del cual el sujeto podía encontrar un lugar estable en la sociedad. En efecto, los procesos de flexibilización laboral desafían al trabajo como mecanismo de integración social. Si bien se sigue confiando en él como si fuera central, "falla tanto en asignar un 'sitio' en la sociedad a un creciente número de personas, como en proporcionarles ingresos y protección adecuados" (Offe, 1997, p. 13), haciéndose más inestables e inseguros los tránsitos de inserción social incluso para profesionales universitarios.

A pesar de lo anterior, en Chile la investigación en torno a los efectos sociales y subjetivos de los cambios en el trabajo se ha orientado preferentemente al análisis de la "exclusión" (desempleo, subempleo, etc.), dejándose de lado el estudio de cómo hoy, a través del trabajo, se construye qué tipo de inclusión social. Esfuerzos recientes muestran un giro al respecto, entre los cuales podemos considerar a los estudios y seminarios que ha venido realizando el Centro de Estudios de la Mujer (ver Díaz et al., 2006), así como la compilación realizada por Álvaro Soto (2008).

A través del presente artículo se espera contribuir a este esfuerzo mediante la presentación de algunos de los resultados obtenidos a partir de una investigación 
orientada a comprender cómo en el Chile contemporáneo se están construyendo las identidades en el contexto de la flexibilización laboral. En esta se tuvieron dos consideraciones fundamentales. La primera se refiere a que el proceso de inclusión social a través del trabajo tiene como un momento clave al período comprendido entre los 24 y los 35 años (a menudo denominado como adultez-joven). Es en este período que la mayor parte de los sujetos realiza el tránsito entre educación y trabajo, y es ahí donde se asienta la demanda social de lograr un sitio estable en la sociedad que, mediante el trabajo, sostenga un proyecto de emancipación familiar propio (Casal, 1996 y 1997). Un segundo elemento que se tuvo en cuenta se refiere a que son los profesionales universitarios los que estarían mejor posicionados para moverse exitosamente en el contexto de un mercado laboral flexible. Según Casal (1996 y 1997) son los trabajadores con este tipo de formación los que desarrollarían transiciones al mundo del trabajo de aproximación sucesiva, orientada al logro de expectativas más bien altas de desarrollo profesional y de posicionamiento social, las que se van cumpliendo paulatinamente.

Así, esta investigación se ha abocado al estudio de las narrativas identitatarias que desarrollan adultos jóvenes profesionales para explicar su situación laboral y su ser trabajador. Se busca comprender qué identidades laborales son producidas a través de los nuevos caminos de inclusión social que ofrece este nuevo ordenamiento laboral. Mediante un enfoque narrativo-discursivo se abordan los relatos de los sujetos como formas de acción social, analizando los recursos mediante los cuales el sujeto se posiciona de un cierto modo como actor social.

Este artículo se organiza en tres partes. En la primera se describen los procesos de flexibilización laboral en el contexto nacional, proponiendo que la flexibilización laboral tiene un correlato subjetivo que debe ser investigado. En la segunda se desarrolla la perspectiva narrativo-discursiva como un enfoque que puede ayudar a comprender cómo los relatos de la propia vida laboral contienen elementos estructurantes que revelan formas de inteligibilidad social contingentes, mostrando cómo las construcciones de sí se articulan con las formas validadas de ser. Desde ahí, en una tercera parte, se abordan algunos de los resultados más significativos de la investigación, describiendo algunos de los principales elementos que organizan las identidades de estos sujetos construyéndose en el contexto de la vinculación laboral flexible.

\section{La flexibilización laboral en Chile y sus desafíos a la identidad}

En Chile los procesos de flexibilización se desarrollaron muy tempranamente, mucho antes que ocurriesen los cambios económicos y políticos que describe Castells (1997), y que los modelos de gestión emergentes en los ochenta exigieran estas transformaciones. El golpe militar será fundamental en lo que 
Moulian (1997) ha llamado la revolución neoliberal. Efectivamente, al poco tiempo de comenzado el régimen militar, el grupo de economistas conocido como Chicago Boys, discípulos de Milton Friedman, tomó el control económico del país, amparados por el terrorismo de Estado, lo que dificultó cualquier resistencia articulada. Hoy el modelo propuesto e implementado por ellos se mantiene sin variaciones sustantivas.

Tal como describe López (2004; p.118), la reforma neoliberal de la legislación laboral no tenía la intención de responder a problemas ocupacionales coyunturales, sino que fue la "forma de realizar un ideal de sociedad supeditada al funcionamiento del mercado, que de hecho operó como una severa reforma estructural para reducir la protección legal sobre el trabajo. El objetivo era diseñar un mercado de trabajo afín a la política económica de apertura unilateral y de potenciación de los sectores exportadores de materia prima, lo que fue complementado con una estrategia generadora de empleo basada en el uso intensivo de mano de obra poco calificada y barata. Para ello fue preciso aplicar un intenso ajuste legislativo que implicó liberar de regulaciones las modalidades de contratación laboral, el despido y las condiciones de trabajo, y a la vez restringir intensamente el ejercicio de la libertad sindical y la negociación colectiva” (López, 2004, p.119). Fue así que en Chile, "a partir de 1978, se derogó legalmente la estabilidad en el empleo mediante el reconocimiento expreso de la libertad empresarial de despido y el uso extenso de un abanico de modalidades contractuales de duración limitada, todo ello debido a una decisión política de transformar el sistema laboral" (López, 2004; p.128), y no a una demanda proveniente, ya sea de una situación coyuntural de desempleo o de una necesidad de aumentar la competitividad global de las empresas.

Si bien las reformas laborales realizadas desde 1990 (particularmente las de 1994 y 2001) han intentado elevar el nivel de protección legal del trabajo, paralelamente también han continuado con el proceso de rebaja de los costos de la contratación laboral (López, 2004); manteniéndose la individualización de las relaciones laborales y articulando ahora este marco regulativo con las nuevas formas de gestión organizacional. Actualmente, la ley no se propone garantizar el derecho al empleo; por el contrario, su principal función es facilitar y promover las prácticas contractuales asociadas a la gestión por competencias, defendiendo al trabajador ya no como sujeto colectivo y al interior de su empresa, sino al trabajador como individuo desenvolviéndose en el mercado de trabajo. Así, promover la empleabilidad del trabajador se constituye en el nuevo deber fundamental del derecho laboral (López, 2004): "La novedad se refiere a establecer como nuevo objetivo político jurídico en materia laboral el facilitar la colocación o recolocación en un escenario que se define como móvil, cambiante e inestable laboralmente" 
(López, 2004; p. 150), individualizando definitivamente la relación laboral (Acuña y Pérez, 2005).

Como señalan Acuña y Pérez (2005), los estudios de empleo realizados en Chile no logran diferenciar de modo exhaustivo las formas de vinculación laboral de los sujetos; sin embargo, abordando la movilidad laboral de los trabajadores chilenos, la Dirección del Trabajo ha confirmado que esta es sumamente significativa: más del $78 \%$ de la fuerza de trabajo se moviliza en un plazo de sólo 18 meses (Henríquez y Uribe-Echeverría, 2004).

Esta realidad de vinculación laboral flexible no excluye a los profesionales, tal como lo plantean Sapelli (2005) y Gatica y Romaguera (2006), quienes indican que justamente es en el grupo de trabajadores profesionales con mayor tiempo de estudios donde está aumentando dramáticamente el desempleo, particularmente entre los profesionales más jóvenes. Según estudios de la Consultora Entrepreneur (2005), esto se debería a que las empresas están cambiando radicalmente los puestos fijos de profesionales por formas de vinculación flexibles a través de contratos temporales, por tarea, por proyecto, a través de prestaciones de servicios profesionales o mediante la externalización de funciones. Así, el 58\% de los despidos corresponde a profesionales mayores de 36 ańos, los mayores de 46 son los más protegidos correspondiendo sólo a un $2 \%$ de los despidos, y los profesionales de 35 y menores corresponden al $40 \%$ de los despidos. Es necesario tener en cuenta que son justamente estos los que reemplazan a los mayores, siendo contratados vía outsocurcing, prestación de servicios profesionales, por proyecto, o con contratos temporales (por lo tanto no hay despido propiamente tal); siendo sólo un 41\% de los profesionales quienes encuentran trabajo en empleos fijos con contrato, lo que coincide con las últimas estadísticas del seguro de desempleo (SAFP, 2006).

Si el trabajo había sido entendido como el principal dispositivo de integración social, los caminos que hoy ofrece resultan mucho más complejos y frágiles, incluso para aquellos que tienen mayor formación, haciéndose más intrincada la relación entre educación y trabajo (Ripoll, 1995; Casal, 1996 y 1997; Albaigés, Sisto y Román, 2003 y 2004; Sisto, 2005 y Sapelli, 2005). Esto necesariamente afecta las trayectorias de inserción social que van realizando los sujetos, mediante las cuales se constituyen en actores sociales legítimos.

Tal como ha planteado Dubar (2000a), estos cambios en los modos de vinculación laboral afectan el cómo nos estamos construyendo como sujetos a partir del trabajo, por ello va a describir a esta transformación como una "crisis social y simbólica", pues lo que está cambiando es el "modo de identificación de los individuos" (p. 1). En efecto, si, junto a diversos autores (Vygotski, 1978; Tajfel, 1984; Bruner, 1990; Dubar, 1991; entre muchos otros), consideramos que la 
identidad es construida y reconstruida a partir de la acción social, donde el sujeto va conformando una autonarración biográfica que genera unidad y continuidad temporal a partir de la heterogeneidad de la experiencia (Dubar, 1991; Íñiguez, 2001; Freytes, 2004); y si a ello sumamos la centralidad del trabajo en la vida social, las nuevas formas de vinculación laboral desafían los modos como habían sido construidas las identidades sociales de los sujetos.

Precisamente la investigación en torno a estas transformaciones identitarias está ocupando a gran parte de las ciencias sociales contemporáneas. Autores como Sennet (1998), Bauman (1998a, 1998b; 2000), Gorz (1991), Dubar (1991; 2000a), Du Gay (1996) y Beck (1991), entre otros, han notado cómo las nuevas identidades se estarían construyendo en base a nuevos vectores, tales como el individualismo, la estética del consumo y el rechazo a relaciones sociales estables. Bauman (1998a, 1998b y 2001), Gorz (1991), Beck (1991) y Sennett (1998), han coincidido en señalar que la flexibilidad laboral tiene como correlato subjetivo el desarrollo de nuevas teleologías personales orientadas a la "maximización de libertad", al autodespliegue y realización individual, no colectiva, instalándose como criterio de juicio la estética del consumo y la satisfacción de los propios deseos (Bauman, 1998a). En este contexto, Dubar (2000b) advierte que las formas de identidad emergente se caracterizan por la primacía del sujeto individual por sobre las pertenencias colectivas, así como de las identificaciones "para sî" por sobre las identificaciones "para los demás”. Lo central es la realización personal en un contexto de fuerte competencia. Por ello, Dubar señala que si esta es la forma de acción social premiada por el actual contexto, entonces "es que hemos entrado en una crisis identitaria permanente" (Dubar, 2000b, 127).

Tal como podemos apreciar, la transformación de la naturaleza del trabajo está determinando los actuales modos de constitución identitaria, y esto tiene profundos efectos tanto sobre las trayectorias laborales y personales que los sujetos realizan, así como sobre las formas de vinculación social que emergerán de estas identidades.

Sin embargo, la investigación empírica en torno a cómo son realizados estos procesos de construcción identitaria resulta aún escasa. Siguiendo a Wetherell (2007), es necesario "desempaquetar" a este sujeto descrito desde el análisis macrosocial; comprenderlo en su ocurrencia cotidiana y contradictoria, centrándose en las mismas prácticas sociales donde es construido. Mediante el análisis empírico de los relatos biográficos emergen no sólo los discursos predominantes que apelan a los sujetos reproduciendo el ordenamiento social, sino que además es posible analizar cómo estos discursos son realizados localmente produciendo subjetividades. Es ahí que emerge la heterogeneidad y la contradicción, como parte constitutiva del hacerse sujeto, y es ahí donde se evidencian los esfuerzos del agente 
biográfico por generar una coherencia a la narrativa identitaria que le haga calzar con las demandas sociales predominantes. Para responder a esta demanda, en esta investigación hemos tomado un enfoque narrativo discursivo.

\section{El enfoque narrativo discursivo para analizar las narrativas identitatarias}

Este enfoque aborda a las identidades, más que como una estructura permanente que se revela en el relato, como una performance. Su mirada se sitúa en las prácticas sociales mediante las cuales es realizada una identidad, respondiendo a la heterogeneidad de la relación social; en esto son claves las prácticas mediante las cuales damos cuenta de nosotros y nos posicionamos de cierto modo en el contexto social. De ahí la relevancia de las narrativas identitatarias. Estas son construidas dirigiéndose a las circunstancias inmediatas, a la práctica de dar cuenta de sí, siendo moldeadas por estas, así como también por las formas de ordenamiento social (Taylor y Littleton, 2006). Siguiendo a Tajfel (1984), es a través de las categorías sociales disponibles para la identificación de los sujetos que estas formas de organización social se expresan a nivel subjetivo. Así, los significados mediante los cuales el sujeto se hace inteligible como actor social, tanto frente a los otros como frente a sí mismo, emergen de categorías establecidas previamente, de las valoraciones asociadas a ellas y de las consecuencias o efectos sociales de esas identificaciones (Taylor y Littleton, 2006). En este sentido, se sigue el modelo dramatúrgico desarrollado por Goffman (1959) según el cual la identidad se elabora en función de los estándares sociales ideales para la posición social en la cual está dispuesto el sujeto. Es bajo este mandato que la identidad se construye narrativamente, organizando la diversidad que compone la experiencia subjetiva en torno a un eje que genere una versión de sí coherente y consistente, tanto para sí como para otros, con el fin de hacer al sujeto inteligible como actor social legítimo según las versiones de sujeto aceptables y deseables (Gubrium y Holstein, 1998).

Por lo tanto, las narraciones identitarias no son consideradas como representaciones de estados interiores del individuo, sino más bien como acciones sociales. Lo que importa, por lo tanto, es lo que hace el sujeto cuando habla de sí, situándose a sí mismo de un cierto modo en su contexto social. Este acto de posicionamiento es realizado utilizando las narrativas dominantes o canónicas como recursos en el trabajo de construir una versión de sí (Bruner, 1987 en Wetherell, 2007). Los hablantes están limitados en su trabajo identitario por las narrativas culturales disponibles, las que sugieren qué tipo de historias pueden ser contadas y qué tipo de consecuencias tiene el contarse de cierto modo. Así, el análisis desde una perspectiva discursiva permite abordar cuáles son esas na- 
rrativas a las cuales el sujeto responde, y qué consecuencias tiene su uso para la posición del sujeto en lo social: qué tipo de derechos, deberes y responsabilidades le son asignadas por estas narrativas, a qué lo habilita, cuáles son las teleologías que orientan su acción y qué acciones le están limitadas (Reynolds, Wetherell y Taylor, 2007).

Uno de los mecanismos que hace más evidente la manera cómo las narrativas dominantes se expresan en el trabajo identitario es el control narrativo. Este se refiere a las diversas estrategias que emergen a lo largo del proceso de narrarse a sí mismo, a través de las cuales los diversos recursos desplegados son organizados con el fin de dar una versión coherente de sí mismo. El "caos experiencial" (Gubrium y Holtein, p. 166) que constituye lo subjetivo se organiza en formas coherentes y descifrables. Las narrativas son conectadas y ensambladas bajo los mandatos, constricciones, teleologías, que caracterizan esos contextos (grupos, instituciones, incluso discursos sociales dominantes). En este sentido, Denzin plantea que "el punto no está en si la coherencia biográfica es una ilusión o una realidad, más bien lo que se debe establecer es cómo los individuos dan coherencia a sus vidas cuando ellos escriben o hablan sus propias autobiografías. Los orígenes de esta coherencia, las narrativas que yacen tras las ideologías que las estructuran, deben ser descubiertas" (Denzin 1989 en Gubrium y Holstein, 1998, p. 165).

De modo que el abordaje discursivo de las narrativas identitarias permite dar cuenta de qué sistemas de significación están apelando a los sujetos, permitiendo mostrar los vínculos entre las formas de ordenamiento social constituidas simbólicamente y los modos como nos construimos a nosotros mismos. Junto a lo anterior, al situar la mirada en aquellas desplegadas en la práctica cotidiana, esta perspectiva permite no sólo observar estas narrativas dominantes en su proceso de despliegue, sino que además cómo éstas se encuentran con otras en el proceso de construcción del relato de sí. Contar una narrativa de vida es una acción situada. La interacción con otros hablantes hace que la historia pueda ser trabajada de modos diversos de acuerdo a cómo se va construyendo la conversación (Reynolds, Wetherell y Taylor, 2007). Pero el despliegue narrativo de sí no sólo toma en consideración las narrativas dominantes y la situación inmediata en la cual se produce, sino que también responde a despliegues narrativos previos, y por lo tanto responde a posicionamientos previos, otras historias en otros contextos que pueden ser profundamente diversas, incluso contradictorias con los posicionamientos actuales (Taylor y Littleton, 2006). Es en este contexto que el trabajo narrativo de hacer identidad se efectúa tomando posición frente a distintas audiencias, presentes y previas, de modo que en el despliegue efectivo de este trabajo narrativo distintas versiones de sujeto se intersectan, pudiéndose generar 
inconsistencias. Son estas las que tensionan las narrativas dominantes en este trabajo de hacerse a sí mismo.

De este modo, la perspectiva discursiva permite abordar los sistemas de significados que dominan la construcción narrativa del sí mismo, así como los posibles conflictos y contradicciones que surgen en su despliegue efectivo en la realización de sujetos concretos, haciéndose inteligibles como actores sociales.

\section{La investigación}

Lo que aquí se presenta es parte de una investigación a dos años plazo, que pretende describir y analizar las construcciones de identidad laboral que desarrollan adultos-jóvenes profesionales en condiciones de vinculación laboral flexible, y los efectos de estas construcciones sobre los procesos de vinculación social.

Se seleccionaron 32 sujetos, 16 hombres y 16 mujeres entre 25 y 34 años de edad, pertenecientes a dos de las carreras de mayor demanda de matrículas en Chile: ingeniería comercial (management) y psicología, titulados de las universidades que según el Banco Central de Chile serían las mejor consideradas por el mercado laboral, y con al menos 3 años de experiencia profesional. Todos los entrevistados estaban vinculados laboralmente bajo condiciones flexibles. Para esta investigación se entiende que hay vinculación laboral flexible cuando el 50\% o más del ingreso del trabajador proviene de una relación laboral no amparada por contrato indefinido con salario fijo. Esto incluye personas con contratos a plazo fijo, de comisionista, por tarea o proyecto, así como aquellas que trabajan como prestadores de servicio (a través de boletas de honorarios), entre otros.

Se realizaron dos entrevistas individuales activo-reflexivas a cada sujeto. La entrevista activo-reflexiva es una interacción en la cual los dos partícipes (entrevistador y entrevistado) interactúan como sujetos en una conversación abierta, guiada por una pauta temática. Este tipo de entrevista permite generar mayor diversidad discursiva, en un encuentro distendido que más se asemeja a una conversación entre amigos o conocidos que a un interrogatorio policial (Holstein y Gubrium, 1995; Denzin, 2001).

Las entrevistas fueron grabadas con un aparato magnetofónico y luego transcritas según convenciones de trascripción basadas en el sistema de Jefferson, que permite destacar características del habla relevantes en la interacción (Sacks en Potter, 1996). Este sistema, que es ampliamente utilizado en etnometodología (Sacks en Potter, 1996), permite destacar mediante los símbolos disponibles en una máquina de escribir o procesador de texto las características del habla que los analistas conversacionales y de discurso consideran como relevantes en la interacción. A continuación se detallan algunos elementos de este sistema (ver Potter, 1996; p. 293-294): 
- Subrayar (se largó) indica palabras o partes de palabras que son acentuadas por el hablante.

- Los dos puntos (:) marcan la prolongación del sonido inmediatamente anterior (en:tonces), y cuantos más haya más larga es la prolongación (Ah::::)

- Las flechas preceden a subidas y bajadas marcadas de entonación ( $\uparrow$ Muy bi $\downarrow$ en).

- El interrogante final marca una entonación interrogativa. Cabe señalar que no existe una correspondencia necesaria con expresiones que los participantes tratan como preguntas.

- Un punto final marca una entonación completa, no necesariamente un punto gramatical.

- La coma marca una entonación continua, no necesariamente una coma gramatical.

- Un guión (gra-gra:cias) marca una finalización brusca y perceptible de una palabra o sonido.

- Los corchetes marcan el inicio y final de una superposición en el habla ([ ]).

- Cuando se produce un cambio de turno sin interrupción se marca mediante el símbolo igual (=)

- Los números entre paréntesis $(0,2)$ reflejan la duración de las pausas en segundos; un simple punto entre paréntesis (.) marca una pausa audible pero demasiado breve para medirla.

- Las expresiones más sonoras se escriben en mayúscula.

- Cuando la persona que hace la transcripción tiene dudas sobre una palabra o expresión la pone entre paréntesis; si no puede resolver las dudas coloca unos paréntesis vacíos.

- Los comentarios clarificadores se colocan entre doble paréntesis ((se levanta)).

- La omisión del material de una cinta por razones de brevedad se indican encerrando tres puntos entre corchetes [...]

- El código que se coloca al final de una transcripción indica información de procedencia del fragmento; en este caso S1:4 indica que el fragmento corresponde a la entrevista realizada al primer sujeto $(\mathrm{S} 1)$ y aparece en la cuarta página de la transcripción $(: 4)$

El material producido fue examinado mediante el análisis del discurso tal como ha sido propuesto en el ámbito de la Psicología Social (Potter y Wetherell, 1987; Reynolds, Wetherell y Taylor, 2007; Wheterell, 2007). Como se señaló, 
esta perspectiva analítica considera a las producciones lingüísticas como formas de acción social. El discurso, por lo tanto, es el "conjunto de prácticas lingüísticas que mantienen y promueven ciertas relaciones sociales" (Ibáñez e Íñiguez, 1996; p. 75). El Análisis de Discurso estudia "cómo esas prácticas actúan en el presente manteniendo y promoviendo estas relaciones” (Ibáñez e Ińiguez, 1996; p. 75). Por lo anterior, la interpretación se apoya en un análisis fundamentalmente pragmático, mirando al lenguaje, a las explicaciones y descripciones, como formas de acción social.

\section{Análisis y resultados}

En este artículo presentaremos tres formas de acción que aparecen concurrentemente en los datos. La primera refiere a cómo el sujeto se hace inteligible socialmente mediante la figura del individuo emprendedor autor de su propia trayectoria. La segunda forma de acción se realiza mediante la descripción de la situación de vinculación flexible como riesgosa, incluso doliente. Finalmente la tercera forma de acción que veremos en este artículo es el ejercicio del control narrativo. La narrativa del sujeto doliente concurre con la que presenta un autor de su propia trayectoria. La tensión entre estas dos se resuelve mediante el despliegue de estrategias retóricas que permiten no sólo explicar el reclamo del sujeto doliente, sino que resignificarlo, poniendo "en su lugar" a esa forma de acción, es decir haciéndola coherente con las narrativas canónicas.

\section{Yo soy el autor de mi propia trayectoria}

La totalidad de las entrevistas presenta como característica el hecho de que, desde el comienzo, el entrevistado desarrolla historias que continuamente lo ponen a él como agente de su propio devenir, eligiendo cada uno de los momentos de su trayectoria laboral. El siguiente fragmento, donde A es el entrevistador y B la entrevistada, sirve para ilustrar varios matices de esta narrativa.

El fragmento se sitúa en el contexto del relato que hace la entrevistada de su trayectoria laboral de los últimos años, que hasta ese momento había sido caracterizada como de vinculación laboral flexible.

\section{Fragmento 1:}

1. A: (...) el tema de ser (flexible::) laboralmente (.) te acomoda, te (desacomoda:) (.) te gustaria (ser:)?

2. B: No, yo he tenido (.) distintas oportunidades pa poder no ser flexible y he tenido la oportunidad de no serlo (.) y m-me limita muchisimo (.) a mi me 
limita mucho (0.1) (...) cuando te quedai sin trabajo (...) y te quedai sin $\downarrow$ pega (.) sin nada (0.2) y desde ahi decidi, que yo no pod ia (0.2) (em:::) no podia poner las los huevos en la misma canasta.

3. A: Ya (.) cuando tú me decís no flexible me e-estay hablando asi como (contrat $\uparrow a:: d a)$ o con sueldo a fin de mes seguro todo eso...

4. B: Contratada si, claro (...)esta sensación de tener (e:h) un horario fijo, todos los dias jornada compl $\uparrow$ eta te limita ene, porque no te deja poder desarrollar proyectos dist $\uparrow$ intos y establecer (.) como proyectos distintos a nivel profesional (0.1) y a nivel personal (.) pa mi, es un tema de decir sabis si no te gusta como soy, si no te gusta mi pega, o teni un problema conm $\uparrow$ igo, o sea yo agarro mis huevadas y me voy (.) no dependo de ti (0.1) esa sensación de no depender (.) de que, de que el empleador no n-(.) o sea que que tú al responderle al empleador (.) no estay comiéndote la mano que te da de comer (.) es una sensación que te da poder pa poder mov $\uparrow$ erte en distintas partes (.) entonces yo ahi aprendi que en realidad la forma mas, mas adecuada pa poder sentir que uno tiene el pod $\uparrow$ er es efectivamente:: el poder mantener distintos tipos de trabajo, en los cuales tú eres el jefe de tu propio trabajo, entonces efectivamente::: (e:h) no $n$-n-no teni que rendirle cuentas a nadie.

En el primer turno de habla el entrevistador le propone evaluar su situación de flexibilidad laboral. Ante esto la informante no responde directamente ante la invitación del entrevistado, sino que se orienta a establecer en el relato que su situación laboral es producto de una elección. El "No, yo he tenido (.) distintas oportunidades pa poder no ser flexible y he tenido la oportunidad de no serlo" instala un supuesto conocimiento en el otro que debe ser rebatido: si está en condición laboral flexible es porque no puede estar bajo una vinculación laboral estable. Ante esto, la sujeto responde el "No (...)". Con lo cual se presenta como eligiendo libremente su condición laboral actual frente a la otra (la estable) que ante otros (el entrevistador, por ejemplo) pudiese ser más deseable. El entrevistador, en este caso, aparece como representante de ciertos discursos sociales que continúan considerando a la estabilidad laboral como la situación más deseable.

En ese mismo turno de habla la informante se describe como habiendo estado sujeta a una vinculación laboral estable, que es descrita como limitante. Sin embargo, esto es realizado a través del uso del "me limita", lo que, puesto en el contexto del fragmento, tiende a reforzar la versión de sí como agente. Es ante este sujeto que se mueve por sí mismo que el trabajo estable se constituye como limitante, lo que será enriquecido en el cuarto turno de habla. Aquí la limitación es significada a partir de la oposición entre el "poner los huevos en 
la misma canasta" del trabajo estable, versus el opuesto, la vinculación flexible, “(...) tener los huevos en diferentes canastas". Así la estabilidad es desplegada en el relato como riesgosa. La valoración de riesgo se realiza mediante la afirmación de que los trabajos estables son inseguros, en tanto sólo se está en un lugar, a diferencia de la flexibilidad que permitiría estar vinculado a más posibilidades laborales.

Es así como la informante se presenta como eligiendo activamente la situación flexible laboralmente a través del "decidí". El presentarse como eligiendo libremente la propia posición tiene el efecto de hacerse inteligible ante el otro y ante sí mismo de una cierta manera: la del sujeto que es autor de su propia trayectoria laboral. Su trayectoria depende de la agencia del individuo.

El $4^{\circ}$ turno de habla de este fragmento resulta particularmente significativo. La participante refuerza su descripción de sí en tanto libre electora de su condición laboral, justificándola a partir de una determinada descripción de la estabilidad. Los argumentos que expone la hablante muestran cómo la vinculación laboral estable descrita como el "horario fijo", "todos los días jornada (compl $\uparrow$ eta) te limita ene", es opuesto a las imágenes del autodespliegue y realización individual del sujeto: "no te deja poder desarrollar proyectos (dist $\uparrow$ intos) y establecer (.) como proyectos distintos a nivel profesional (0.1) y a nivel personal".

El rechazo a la estabilidad laboral sirve por lo tanto para erigir a la condición laboral flexible como una condición de libertad, pero sobre todo de control: "uno tiene el (pod $\uparrow$ er) (...) tú eres el jefe de tu propio trabajo, entonces (efectivamente:::) (e:h) no n- n- no tení que rendirle cuentas a nadie". La descripción de este 'poder' se centra en la agencia individual del sujeto para poder desvincularse. La situación laboral flexible es descrita con una narrativa cosificadora. Es así, uno tiene el poder. Con esto refuerza la verdad de lo dicho. Pero junto con ello también se evidencia una cierta teleología: la de la no dependencia, la de la libertad individual, en la cual "no tení que rendirle cuentas a nadie". Eso es lo deseable, el modelo que rige lo que debemos ser.

Así, mediante la desacreditación del trabajo estable, se refuerza la posición del trabajador bajo condiciones de flexibilidad laboral. Los argumentos que son presentados para desacreditar el trabajo estable traen consigo modelos de ser que rigen la valoración de cada situación, justificando la vinculación laboral flexible como la posición que permite constituirse como libre elector, autor de la propia trayectoria, alguien que tiene capacidad de decidir y además elegir situaciones que ante otros, como el entrevistador, puedan parecer menos deseables, presentándose como teniendo éxito en esta aventura. Este tipo de narrativas caracterizan el eje en torno al cual los sujetos construyen la coherencia de su relato. Tal como podemos apreciar esto tiende a calzar con la figura del emprendedor individual, que emerge 
como ícono de las nuevas formas de ordenamiento social (Beck, 1991; Sennet, 1998; Dubar, 2000b).

Sin embargo, esta narrativa no se desarrolla sin conflicto. A través de la entrevista activo- reflexiva, los hablantes tienden a desarrollar variabilidad discursiva, emergiendo otras formas de construir la situación de flexibilidad laboral que entran en conflicto con la versión del sujeto libre y autónomo que elige su propia trayectoria.

\section{El emprendedor en problemas: el sujeto doliente}

En efecto, el reverso de la figura del emprendedor emerge a través de narrativas que se caracterizan por utilizar una serie de términos, imágenes y metáforas, que tienden a coincidir en dar cuenta a un cuerpo doliente. El reclamo, por lo tanto, es externalizado, no es una inquietud propia la que reclama, sino que es el cuerpo que demanda al sujeto, o lo limita.

\section{Fragmento 2:}

Sabis que hay un tema que es super heavy respecto de esto, que tiene que ver con el tema de la maternidad (0.2) cualquier mina que está trabajando y se embaraza (.) es un cacho (.) pa todo (.) pero (adem $\uparrow$ ás) de ser un cacho pa todos, cuando eri independiente (.) de (verd $\uparrow$ ad) que a mi me costó ( $m \uparrow$ ucho) (.) volver a reinsertarme luego de haber parido al Matías (.) como (que:) tener un ( $\downarrow$ pendejo), de cinco meses cuatro meses (.) es un cacho pa todos los empleadores.

\section{Fragmento 3:}

B: Igual esas pegas (...) implican, o sea ene cansancio, (.) de agotamiento, cachay? (0.1) O sea te cagay fisicamente po' huevón, y psicológicamente. Por ejemplo lo que estoy haciendo ahora los asesoramientos técnicos que les comentaba, (.)es ene pega po', cachay? Puta pero tu decí, puta que tení cara de cansado, porque estoy cansado, cachay, estoy cansado.

\section{Fragmento 4 :}

[...] lo peor es cuando se cumple el plazo de cuando deberías esperar que te llamen y no te llaman, porque la mayoria, la mayoría de las instituciones no te dicen oye, (eh:) no, no, no te llamamos, hay muchas que no llaman más [...], entonces ya, eso, ya, situaciones como esa me han generado que, sentirme igual desanimado, (eh:) me afecta como la eh, el estado de ánimo con que ando en la (ca:sa) cachay?,) [...] 
Los tres fragmentos utilizan recursos más o menos similares para construir una posición de sujeto basada en la dificultad, el dolor corporal y el sufrimiento psicológico. Este tipo de narración contrasta con aquel estilo narrativo mostrado como propio de los sujetos emprendedores (autorresponsables y autores de su propio éxito). Mediante el uso de figuras tales como "un tema que es super heavy respecto de esto", "Igual esas pegas (...) implican", "lo peor es", los hablantes ponen a la vinculación laboral flexible como objeto de una descripción desacreditadora. Siguiendo a Gergen, esto es un modo de dar voz a una experiencia de subordinación frente al poder (en Potter y Weatherell, 1987). Parker (1992) señala que estos discursos intentan promover al sujeto hablante, ya que la retórica de la denuncia actúa generando una distancia entre el sujeto y lo denunciado, lo que tendría el efecto de promover la posición subordinada y sancionar la opresión.

Si bien estamos de acuerdo en que este tipo de narrativa establece una distancia, y por lo tanto ejerce una resistencia respecto a las apelaciones del discurso emprendedor, es necesario fijarse más en detalle en cómo se expresa esto. La narrativa emprendedora, con gran fuerza retórica, despliega una teleología clara: la del individuo emprendedor que construye individualmente su propia trayectoria. Esta teleología funciona normativamente, estableciendo lo deseable y lo no deseable, prescribiendo el sentido de las acciones que harán del sujeto un actor válido para esos criterios de validación contingentes.

Sin embargo, la narrativa de denuncia no opone otras teleologías que supongan otros criterios de valoración y prescriban modos de acción diversos. La distancia con el discurso emprendedor es encapsulada a través de su circunscripción en ciertos elementos tratados narrativamente como objetos con límites sólidos: "tener un ( $\downarrow$ pendejo), de cinco meses"; "ene cansancio", “agotamiento", "el estado de ánimo con que ando". El pendejo, el cansancio, el agotamiento, el estado de ánimo, tal como aparecen en el relato, quedan ceñidos a un objeto que afecta al sujeto, pero que no lo constituye. Es decir, la resistencia se expresa como un malestar, pero este malestar es encapsulado a través de la constitución de objetos limitados en el habla que aparecen como externos a la identidad del sujeto.

A pesar de lo anterior, esta narrativa tensiona el relato de sí, pues apela al sujeto como protagonista. Lo que parece claro en los dos últimos fragmentos: "te cagay fisicamente po' huevón, y psicológicamente", "sentirme igual desanimado". En ambos textos el sujeto se describe en primera persona. En el primero de un modo activo y en el segundo de un modo pasivo, pero apelado al fin. Es así que es problematizada la imagen del sujeto emprendedor, autor de su propia trayectoria.

El hecho de que la resistencia tome este formato no articulado, sin un cuestionamiento a las teleologías dominantes y menos con una teleología alternativa, se liga a que los recursos con los cuales el hablante puede construir, categorizar 
y categorizarse, demandar, en definitiva, hacerse una identidad, emergen de las narrativas socialmente disponibles. El hacerse a uno mismo, por lo tanto, es una labor que se realiza a partir de los sistemas de significación y categorización que están a la mano para contarse a uno mismo. Heilbrun (en Taylor y Littleton, 2006) describe, en relación a los relatos de mujeres, que estas han sido deprivadas de narrativas, textos, categorías, ejemplos, a través de los cuáles podrían asumir poder sobre sus vidas. Lo anterior se puede aplicar a nuestra investigación. La resistencia, que aquí cobra la forma de denuncia, no puede desafiar abiertamente la narrativa canónica, estableciendo alguna otra alternativa. Pero sin embargo sí puede tomar una distancia, tal como lo hemos apreciado, en palabras de Taylor y Littleton (2006) esto es "dar un paso fuera” de la narrativa canónica.

Pero, a pesar de este paso fuera, la narrativa canónica actúa certeramente para hacer calzar lo que ha salido fuera. Tal como se planteó al principio del artículo, estos profesionales adultos-jóvenes, egresados de las universidades mejor posicionadas en el mercado, son los mejor tenidos para ser incluidos socialmente en este nuevo orden y es así como son apelados, y es respondiendo a ello que cumplen la tarea de dar cuenta de sí. Por lo que las tensiones deben hacerse coherentes con ello.

\section{Haciendo coherencia}

El trabajo de hacer identidad implica responder a los "órdenes de persona" que están vigentes para las distintas posiciones, en esto se juega la inteligibilidad social del hablante (Wetherell, 2007). Tal como se señaló, los mecanismos de control narrativo se despliegan con el fin de desarrollar un relato del sí mismo que sea coherente y consistente con las distintas audiencias a las cuales está dirigido: los otros, la circunstancia concreta, el orden sociohistórico contingente e incluso los relatos previos de sí mismo (Gubrium y Holstein, 1998). Este trabajo de control narrativo se muestra de un modo evidente cuando el eje del relato es problematizado y distintos recursos parecen irreconciliables entre sí (Taylor y Littleton, 2007). Es ahí que se debe hacer algo que logre parchar las fisuras resignificando lo que se ha distanciado del eje narrativo.

El siguiente fragmento corresponde a la misma entrevista de la cual se extrajo el fragmento 5. Es necesario dar algunos antecedentes acerca de la estructura narrativa de esta entrevista para comprender la función del fragmento que sigue a continuación. En esta entrevista, si bien el sujeto, durante la primera parte se muestra a sí mismo como un profesional exitoso, invitado a dar charlas, que no necesita buscar trabajo ya que se lo ofrecen; al llegar aproximadamente a la mitad el hablante comienza a relatar que lleva meses sin conseguir trabajo, y que está buscando. El fragmento 4, incluido aquí, corresponde a esos pasajes. Sin 
embargo, al finalizar la entrevista el hablante despliega un evidente ejercicio de control narrativo (Gubirum y Holstein, 1998), resignificando la carencia actual de trabajo.

\section{Fragmento 5:}

B: [...] yo ya estoy trabajando en eso, lo que pasa es que la plata me empieza a llegar el próximo año, entonces no lo considero como (que::)

A: No es ingreso.

B: Claro, no es ingreso, es decir como te digo no me falta que hacer, lo que me falta es plata, o sea de hecho (0.1) estoy, estoy trabajando [...]

Con esto, vuelve a reposicionarse como un trabajador exitoso, aún ante la precariedad descrita precedentemente, que ahora queda reubicada bajo otro contexto ("lo que pasa es que la plata me empieza a llegar el próximo año") explicando las descripciones anteriores, haciéndolas coherentes con el eje bajo el cual es construida la narrativa identitaria.

\section{Discusión y conclusiones}

A lo largo de este trabajo hemos abordado cómo se están construyendo las identidades en el contexto del actual orden laboral. Los resultados que aquí se han mostrado tienden a coincidir con las imágenes aportadas por autores como Gorz (1991), Beck (1991), Baumann (2000), Sennett (1998) y Dubar (2000b), entre otros, quienes describen a las nuevas identidades como construidas poniendo a la propia individualidad como eje de lo social, lo que Dubar ha denominado identificaciones "para sî".

Pero este sujeto, descrito de este modo, se realiza de modos efectivos no como un todo coherente.

Aquí, a partir de una perspectiva narrativa discursiva, se intentó desempacar a este sujeto, indagando en cómo se relatan a sí mismos en su relación con el trabajo; mostrando así qué mecanismos operan para mantener esta aparente coherencia. Uno de los elementos más relevantes que aporta esta perspectiva es que puede mostrar cómo, a pesar de la fuerza que tienen estos discursos dominantes en su realización en identidades concretas, estos son tensados, abriéndose espacios de sutil resistencia. A la vez muestra qué mecanismos son puestos en práctica para mantener el ajuste.

Los mecanismos de control narrativo desplegados no sólo tienen la función de revalidar al narrador ante el oyente o ante sí mismo, en tanto narrador creíble, que cumple las demandas sociales que le son contingentes. La importancia 
de esta actividad reside en que nos permite comprender cómo esas narrativas de sí mismo son un espacio de gobierno propiamente tal.

En efecto, Gubrium y Holstein (1998) han descrito que son estos mecanismos los que mejor permiten ver la conexión entre el ordenamiento social contingente y la manera como nos construimos a nosotros mismos a través de nuestras narrativas identitatarias. Esto es de crucial importancia en el contexto de nuestras sociedades liberales. Si la libre elección individual es la base del ordenamiento social, entonces ¿cómo opera el control social?

Siguiendo a Rose, "las nuevas formas de gobierno que están siendo inventadas en muchas naciones post-estado-de-bienestar al finalizar el siglo veinte, han comenzado a depender, quizás como nunca antes, de la instrumentalización de las capacidades y propiedades de los ‘sujetos de gobierno', y, por lo tanto, no pueden ser entendidas sin dirigirse a estas nuevas formas de entendimiento y acción sobre nosotros mismos y otros en tanto 'seres libres de elegir"” (Rose, 1998; p. 13). Los análisis mostrados justamente calzan con esta descripción. Es en nombre de nuestra libertad, de nuestros deseos, de los tipos de persona que decimos realmente ser, que consumimos comodidades, vestimos nuestros cuerpos, desplegamos nuestras distinciones, construimos nuestras amistades, elegimos nuestra pareja, actuamos (Rose, 1998). Es en nombre de nuestra libertad que asumimos el orden laboral flexible.

El grupo que fue objeto de nuestra investigación, adultos-jóvenes profesionales egresados de las universidades mejor valoradas por el mercado laboral, es justamente el que aparece al centro de las apelaciones para constituirse en un sujeto libre de elegir, responsable por su propia trayectoria. Son estos los discursos que han construido su historia de identificaciones, que es compartida por nosotros, investigadores, en tanto adultos jóvenes profesionales. Es respondiendo a estas apelaciones que nos constituimos frente a lo social como incluidos socialmente, y como actores, sosteniendo, a través de nuestras acciones, lo social.

Sin embargo, estos discursos no operan de un modo homogéneo. Si bien esta es la narrativa dominante de donde extraemos los recursos para construirnos a nosotros mismos, otras narrativas concurren, generando tensiones, aún cuando estas queden encapsuladas. La tensión está. Aquí sólo se mostró un atisbo de aquello. Otros análisis en curso, están mostrado cómo las narrativas de los sujetos provenientes de familias de nivel socioeconómico bajo y medio bajo están hechas respondiendo a este eje discursivo del emprendedor individual, libre elector, pero también responden a otras narrativas de carácter más colectivo comunitario, propias de la historia en la cual se sitúan. En efecto, las narrativas dominantes, a nivel de lo subjetivo, se encuentran con otras versiones de identidad desarrolladas históricamente, que hacen de la construcción de identidad una arena de disputa. Tal 
como han manifestado recientemente varios investigadores del trabajo en Latinoamérica, es hacia esto que debemos dirigir nuestro esfuerzo como investigadores: sacar a la luz estas tensiones, con el fin de dar cabida a la producción de nuevas narrativas que sirvan como recurso para esta producción de nosotros mismos (Antunes, 2007; Battistini, 2005 y 2007b). Es necesario profundizar tanto en esta construcción del sujeto autónomo como en sus contradicciones, para comprender no sólo las formas de vinculación social que serán tejidas desde estos sujetos construidos como actores sociales de este modo, sino también para permitir generar nuevas formas de relación social, en las cuales podamos ser libres de escoger las formas de nuestra libertad.

\section{Bibliografía}

ACuña, E.; PÉrez, E. (2005). Trayectorias laborales: el tránsito entre el trabajo asalariado y el empleo independiente. Santiago: Departamento de Estudios de la Dirección del Trabajo. Disponible en www.dt.gob.cl/documentacion/1612/article-74727.html .

Agulló y Ovejero (20001). Trabajo, Individuo y Sociedad. Madrid: Pirámide.

Agulló, E. (2001). Entre la precariedad laboral y la exclusión social: los otros trabajos, los otros trabajadores, en Agulló y Ovejero, Trabajo, Individuo y Sociedad. Madrid: Pirámide.

Albaigés, B., Sisto, V., y Román, J. (2003). Crisi del treball i emergència de noves formes de subjectivitat laboral en els joves. Col.lecció ESTUDIS. Barcelona: Generalitat de Catalunya.

Albaigés, B., Sisto, V., y Román, J. (2004). Crisi del treball i emergència de noves formes de subjectivitat laboral en els joves (2a Edición) Col.lecció APORTACIONS. Barcelona: Generalitat de Catalunya.

Antunes, R. (2007). Hipótesis y Desafíos para una Teoría de la Transición en Nueva Época. Ponencia presentada en el XXVI Congreso Asociación Latinoamericana de Sociología. 14 de agosto de 2007. Guadalajara.

Battistini, O. (2007b). ¿Volver a lo seguro para resguardar la identidad? Ponencia presentada en el XXVI Congreso Asociación Latinoamericana de Sociología. 15 de agosto de 2007. Guadalajara.

BAtTistini, O. (2004). Las interacciones complejas entre el trabajo, la identidad y la acción colectiva, en Battistini, O. (comp), El Trabajo frente al Espejo. Continuidades y rupturas en los procesos de construcción identitaria de los trabajadores. Buenos Aires: Prometeo.

Bauman, Z. (1998a). Trabajo, Consumo y Nuevos Pobres. Barcelona: Gedisa 2000. Bauman, Z. (1998b). Globalización. Buenos Aires: FCE, 2000.

Bauman, Z. (2000).Modernidad Liquida. Buenos Aires: FCE, 2002.

Beck, U. (1999). El Nuevo Mundo Feliz. Barcelona: Paidos 2000.

Boltanski, L. y Chiapello, E. (1999). Le nouvel esprit du capitalisme. París: Gallimard.

Bruner, J. (1990). Acts of Meaning. Cambridge, MA: Harvard University Press. 
Casal, J. (1996). Modos Emergentes de Transición a la Vida Adulta en el Umbral del Siglo XXI: Aproximación Sucesiva, Precariedad y Desestructuración. Revista Española de Investigaciones Sociológicas. No 75: 295- 316.

Casal, J. (1997). Modalidades de Transición Profesional, Mercado de Trabajo y Condiciones de Empleo. Cuadernos de Relaciones Laborales, No 11. Madrid: Universidad Complutense de Madrid.

Castells, M. (1997). La era de la información: economía, sociedad y cultura. Vol.1. La sociedad red. Madrid: Alianza.

Denzin, N. (2001). The reflexive interview and a performative social science. Qualitative Research Vol. 1 No 1; 23-46.

Diaz, X., Godoy, L., Stecher, A. y Toro, J. P. (2006). Trabajo, Identidad y Vinculo Social. Reflexiones y experiencias en el capitalismo flexible. Santiago: Centro de Estudios de la Mujer.

Dubar, C. (1991). La socialisation, construction des identités sociales et professionelles. París: Armand Collin.

Dubar, C. (2000a). Trajectoires professionnelles, formes identitaires et mondialisation. Ponencia presentada en el III Congreso Latinoamericano de Sociología del Trabajo. 17 -20 de mayo. Buenos Aires. Argentina.

Dubar, C. (2000b) La crise des identités, l'interprétation d'une mutation. Paris: Presses Universitaires de France.

Entrepreneur (2005). Estudio al Mercado Laboral de Ejecutivos 1989-2005. Santiago: Entrepreneur Consultores.

Freytes, A. (2004). La dimensión biográfica y relacional de la identidad profesional, en Battistini, O. (ed.), El Trabajo frente al Espejo. Continuidades y rupturas en los procesos de construcción identitaria de los trabajadores. Buenos Aires: Prometeo.

Gatica, J. y Romaguera P. (2006). El Mercado Laboral en Chile: Nuevos Temas y Desafíos, en Foco No 55. Santiago: Expansiva.

Goffman, E. (1959). The presentation of Self in Everyday Life (La presentación del Yo en la Vida Cotidiana). Amorrortu: Buenos Aires, 2006.

Gorz, A. (1991). Metamorfosis del Trabajo. Búsqueda de Sentido. Crítica de la Razón Económica. Madrid: Ed. Sistema 1997.

Gubrium, J y Holstein, J.A. (1998). Narrative practice and the coherence of personal stories. The Sociological Quarterly, Vol 39, No1: 163-87.

Henríquez, H. y Uribe-Echeverría, V. (2004). Trayectorias laborales: la certeza de la incertidumbre. Santiago: Departamento de Estudios de la Dirección del Trabajo. Disponible en http://www.dt.gob.cl/documentacion/1612/ article-65670.html .

Holstein, J. y Gubrium, J. (1995) The Active Interview. London: Sage.

ÍñIgueZ, L. (2001). Identidad: De lo personal a lo social. Un recorrido conceptual. En E. Crespo (Ed.) La constitución social de la subjetividad. Madrid: Catarata.

Íñıguez, L. y Antaki, Ch. (1994). El Análisis del Discurso en Psicología Social. Boletín de Psicología No 44, pp. 57-75.

López, D. (2004). Derechos, trabajo y empleo. Santiago: LOM. 
Moulian, T. (1997): Chile Actual: Anatomia de un Mito. Santiago: ARCIS/ LOM.

Offe, C. (1997). Precariedad y Mercado Laboral. Un análisis a medio plazo de las respuestas disponibles, en ESK CUIS ¿Qué Crisis? Donostia: Tercera Prensa - Hirugarren Prentsa S. L.

Potter, J. y Wetherell, M. (1987). Discourse and Social Psychology. London: Sage.

Reynolds, J. Wetherell, M y Taylor, S. (2007). Choice and chance: negotiating agency in narratives of singleness, The Sociological Review. Vol. 55 No 2: 331-351.

Ripoll, P. (1995): El desarrollo de carrera en jóvenes de reciente incorporación al primer empleo. Tesis Doctoral. Valencia: Universidad de Valencia.

Rose, N. (1998). Inventing our selves. Psychology, power and personhood. Cambridge: University Press.

SAFP (2006). Estadísticas del Seguro de Desempleo. Enero 2006. Santiago: Superintendencia de Administradoras de Fondos de Pensiones de Chile.

Sapelli, C. (2005) "Desempleo y Capital Humano. en Foco No 51. Santiago: Expansiva.

Sennet, R. (1998). La Corrosión del Carácter: las consecuencias personales del trabajo en el nuevo capitalismo. Barcelona: Anagrama 2000.

Sisto, V. (2005): Flexibilización Laboral de la Docencia Universitaria y la Gest(ac) ión de la Universidad sin Órganos: Un análisis desde la Subjetividad Laboral del Docente en Condiciones de Precariedad, en Gentili, P y Levy, B. (eds.) Espacio público y privatización del conocimiento: Estudios sobre políticas universitarias en América Latina. Buenos Aires: CLACSO.

Smith, B. \& Sparkes, A. (2008). Contrasting perspectives on narrating selves and identities. Qualitative Research. Vol. 8; No5: 5-35.

Soтo, A. (editor) (2008). Flexibilidad Laboral y Subjetividades, hacia una comprensión psicosocial del empleo contemporáneo. Santiago: LOM edicionesUniversidad Alberto Hurtado.

TAjfel, H.: (1984) Grupos Humanos y Categorias Sociales. Barcelona: Ed. Herder.

Taylor, S. y Littleton, K (2006). Biographies in talk: A narrative-discursive research approach. Qualitative Sociology Review. Vol II No 1: 22-38.

Wetherell, M. (2007). A step too far: Discursive psychology, linguistic ethnography and questions of identit, Journal of Sociolinguistics. Vol. 11 No 5: 661-681.

Fecha de recepción del artículo: 10 de julio de 2008.

Fecha de aceptación del artículo: 19 de noviembre de 2008. 